\title{
The effect of Anakinra on Quality-of-Life in a family with colchicine-resistant FMF
}

\author{
J van der Hilst ${ }^{1,2^{*}}$, A Lijnen $^{1}$ \\ From 8th International Congress of Familial Mediterranean Fever and Systemic Autoinflammatory Diseases \\ Dresden, Germany. 30 September - 3 October 2015
}

\section{Introduction}

About $5-10 \%$ of patients with FMF do not to colchicine treatment to control inflammation. In these patients anti-IL1 therapy seems to be effective in controlling inflammation, although clinical trials are lacking. However, many patients on Anakinra experience side effects including headache and injection-site reactions. How Anakinra treatment influences quality-of-life (QoL) in these patients is unknown.

\section{Objectives}

To investigate the effect of Anakinra on inflammation and QoL in a family with a severe phenotype colchicineresistant FMF.

\section{Patients and methods}

Four sisters of Italian descent with homozygote M694Vpositive FMF, had an extraordinary phenotype with continuous inflammation, daily fevers, erysipelas-like skin lesions and serositis. Colchicine was initiated in all patient, but showed ineffective in controlling inflammation. Eventually, Anakinra was initiated. Before and during treatment with Anakinra inflammatory parameters (CRP, leukocyte-count, Serum amyloid A) were measured. One patient only started Anakinra after type AA amyloidosis had developed leading to a renal replacement therapy and renal transplantation. In the other three patients QoL questionnaire (RAND-36) was obtained, before and 4 weeks after start of Anakinratherapy. The study was approved by the local ethical committee. Because of reimbursement was initially declined, Anakinra was discontinued. Later, it could be re-initiated. QoL questionnaires were obtained after stopping and after re-initiation of Anakinra.

Jessa Hospital, Infectious Diseases and Immunity, Hasselt, Belgium Full list of author information is available at the end of the article

\section{Results}

During Anakinra treatment the CRP values were significantly lower than without Anakinra (mean $3.7 \mathrm{mg} / \mathrm{L}$ vs $30 \mathrm{mg} / \mathrm{L}, \mathrm{p}<0.001$ ). The QoL improved significantly after initiation of Anakinra in 5 out of 6 scales of the RAND-36 $(\mathrm{p}<0.05)$. The QoL deteriorated after withdrawal of Anakinra to pre-treatment level and improved again after re-initiation of Anakinra.

\section{Conclusion}

Here we show that Anakinra can effectively suppress inflammation in a family with severe colchicine-resistant FMF. This lead to a significant improvement in quality of life.

\section{Authors' details}

'Jessa Hospital, Infectious Diseases and Immunity, Hasselt, Belgium.

${ }^{2}$ University of Hasselt, BIOMED, Hasselt, Belgium.

Published: 28 September 2015

doi:10.1186/1546-0096-13-S1-P108

Cite this article as: van der Hilst and Lijnen: The effect of Anakinra on Quality-of-Life in a family with colchicine-resistant FMF. Pediatric

Rheumatology 2015 13(Suppl 1):P108.

Submit your next manuscript to BioMed Central and take full advantage of:

- Convenient online submission

- Thorough peer review

- No space constraints or color figure charges

- Immediate publication on acceptance

- Inclusion in PubMed, CAS, Scopus and Google Scholar

- Research which is freely available for redistribution 